\title{
Produção científica em Ciência da Informação: análise temática em artigos de revistas brasileiras
}

\section{Leilah Santiago Bufrem}

Doutora em ciências da comunicação pela USP e pós-doutora pela Universidad Autonoma de Madrid; Professora titular do Departamento de Ciência e Gestão da Informação da Universidade Federal do Paraná.

Helena de Fátima Nunes Silva

Professora Adjunta; Departamento de Ciência e Gestão da Informação da Universidade Federal do Paraná.

Cecília Licia Silveira Ramos e Medina Fabian

Professora Assistente; Departamento de Ciência e Gestão da Informação da Universidade Federal do Paraná

Tidra Viana Sorribas

Bolsista de Iniciação Científica PIBIC/CNPq; Aluna do Curso de Gestão da Informação, da Universidade Federal do Paraná

Analisa o tema Produção científica em artigos de revistas brasileiras na área de ciência da informação. Realiza recorte de 442 títulos de uma base de dados de periódicos nacionais da área de ciência da informação BRAPCI -. Identifica três vertentes de preocupação: a produção científica propriamente dita, em suas manifestações; a análise temática dessa literatura, e as suas formas de expressão, tais como, periódicos, teses, dissertações e literatura cinzenta.

Palavras-chave: Produção científica; Ciência da informação; Revistas científicas; Bibliometria; Comunicação científica.

\section{Scientific production in Information Science: thematic analysis of brazilian journals articles}


An analysis of the thematics of Scientific Production in articles from Brazilian journals in the field of Information Science is presented. A sampling of 314 titles from a database of Brazilian periodicals in the domain of Information Science (BRAPCI) was performed. Three concerning areas were detected: the strictly-speaking scientific production, in its occurrences; the analysis of this production, and the types of production, such as periodicals, theses, dissertations, and gray literature.

Key-words: Scientific production ; Information science ; Scientific journal; Bibliometry; Scientific communication.

Recebido em 12.06.2006 Aceito em 08.11.2006

\section{Introdução}

Para concretizar a reflexão sobre a literatura de um campo do conhecimento faz-se necessário pensar nas diversas possibilidades e suportes dessa produção. Considerando-se a diversidade de produtos, tais como livros, revistas científicas, teses, dissertações, monografias, comunicações em eventos, impõe-se a necessidade de categorizá-los, para somente então, iniciar o planejamento de recortes ou divisão de etapas do trabalho. O que diferencia a produção editorial periódica científica, a forma de expressão privilegiada como objeto deste trabalho, de qualquer outra produção, é o fato de estar vinculada a uma organização editorial e representá-la tematicamente. Deve identificar-se com os propósitos da linha editorial, esperando-se por isso que seja apoiada no processo de seleção por um corpo de consultores especializados.

A análise das revistas científicas tem sido uma modalidade de estudo com presença significativa e reiterada na literatura voltada à produção de conhecimento. Justifica-se o fenômeno especialmente devido à necessidade, sentida pelos pesquisadores, de informações sobre as fontes disponíveis para o domínio, sempre relativo, da literatura de sua área e dos meios existentes para difusão de suas próprias pesquisas. Além disso, a publicação científica tornou-se, em seu processo histórico, um instrumento indispensável não apenas como meio de promoção individual, mas enquanto forma de promoção e fortalecimento do ciclo criação, organização e difusão do conhecimento. Por conseguinte, sua contribuição social é um dos fatores que mais influenciam o ritmo de produção do conhecimento.

Ao defender que qualquer trabalho científico, desenvolvido em determinado contexto social e em dado momento histórico, reflete as mudanças e contradições desse contexto, tanto em sua organização interna ou método, quanto em suas aplicações, Bufrem (1996) argumenta 
que o encaminhamento dado à pesquisa é resultante de opções ou perspectivas situadas concretamente. Como conseqüência desses elementos condicionantes, os estudos sobre revistas científicas situados na literatura recente, mais especificamente nos dez últimos anos, embora com marcante presença dos dados quantitativos como base empírica para reforçar argumentações, revelam uma tendência à análise e interpretação de caráter qualitativo, especialmente justificada pela complexidade de fatores intervenientes nas atividades de produção e divulgação científica.

Os estudos qualitativos sobre essas transformações concretas, constatáveis empiricamente na comunicação científica, são possibilidades ao desafio permanente de compreender e interpretar tendências e modos pelos quais as informações são publicadas, disseminadas, acessadas e usadas. Com esse propósito, o estudo de Janes (2000), sobre a crescente evolução das tecnologias Web constata o profundo impacto dos métodos utilizados na comunicação sobre a atividade escolar, o modo de ler, de escrever e de processar a informação. Ao mesmo tempo, combinando características da Web com o acesso a periódicos científicos e publicações, faz emergir o retrato de um ambiente volátil e dinâmico, a partir do qual é possível discutir sobre os elementos efetivos para a fertilização do processo de crítica e criação do conhecimento.

Em estudo de 2005, Rummler e Silva analisam o tempo de circulação (longevidade) e o alcance geográfico (dispersão) entre os aspectos relacionados com a consolidação de um periódico. Argumentando que os primeiros cinco anos de uma revista podem ser considerados como período probatório para sua sobrevivência, os autores analisam o Catálogo Coletivo Nacional de Publicações Seriadas do Instituto Brasileiro de Informação em Ciência e Tecnologia - IBICT. Nele, identificam 34 periódicos sobre Pesquisa, 42 sobre Ensino e 253 sobre Educação, que têm algum fascículo editado no qüinqüênio de 2000 a 2004. Destes, $73,5 \%, 31,0 \%$ e $36,4 \%$, respectivamente, correspondem a periódicos que têm cinco ou menos anos decorridos desde sua implantação até a edição do fascículo mais recente. Dos periódios que apresentam edições por mais de cinco anos, a mediana de vida é de onze anos (Pesquisa), quinze anos (Ensino) e onze anos (Educação). Cerca da metade dos títulos de cada área são encontrados em bibliotecas institucionais de cinco ou mais Estados da Federação, sendo que 5,9\% (Pesquisa), 21,4\% (Ensino) e $13,4 \%$ (Educação) fazem parte do acervo de bibliotecas de dez ou mais Estados. Como resultado da pesquisa, é apresentado o perfil etário e de dispersão dos periódicos, além de sua identificação pelo título e ISSN, dados que favorecem sua localização em sistemas de busca eletrônica ou física.

Estudos como esses enfocam um tipo de produção científica cujas peculiaridades justificam análises críticas e apreciações fundamentadas em aspectos relevantes do contexto e das condições materiais em que se realizam as pesquisas, especialmente pela posição que assumem para definições que vêm a influenciar processos de avaliação ou decisões por mérito acadêmico. Reforçando essa justificativa, recorremos à Gramsci 
(1988, p. 180), para quem a informação crítica é tarefa de toda revista. Por outro lado, enquanto modo de expressão didática planejado, tendo em vista determinado público leitor, uma revista não pode contentar a todos na mesma medida, razão pela qual deve ser um estímulo e pode se constituir em objeto de multiplicidade de críticas, sinal indicativo de que está no bom caminho.

\section{Aspectos teóricos e metodológicos}

Como ponto de partida para a discussão sobre a relevância e implicações da postura investigativa em qualquer área do conhecimento, o grupo enfoca especificamente o campo da ciência da informação, procurando revelar o seu domínio. Para tanto, as reflexões sobre as especificidades das estruturas sócio-culturais atuantes no campo da ciência da informação determinam que se contemple o enfoque da temporalidade e dos campos de força que permitem o entendimento do seu papel e significado como ciência social.

Foi necessário, portanto, um retrospecto histórico sobre a pesquisa em instituições de ensino superior no Brasil, a partir dos modelos fragmentados de ensino de graduação e cuja atuação foi sendo alterada no período do governo militar. Estas mudanças ocorreram como resultado do acelerado crescimento econômico, acompanhado dos ambiciosos projetos aeroespaciais, que evidenciaram a falta de recursos humanos qualificados para as atividades científicas e tecnológicas com eles condizentes. Tornou-se necessário um enorme esforço com vistas à capacitação de massa crítica no país. A partir de 1968, mais precisamente, devido às contribuições da reforma de ensino e ao modelo da Universidade de Brasília, foram criados institutos centrais, cuja finalidade seria a capacitação de elementos críticos, formados com ênfase na integração entre o ensino e a pesquisa.

O governo passou a investir em ciência e tecnologia, com especial ênfase na pesquisa universitária que, a partir de então e com essas perspectivas, passa a ser financiada quase que exclusivamente pelo Estado. Percebe-se como um continuum, o que seria chamado projeto da modernidade, segundo Coelho Netto (1995, p. 96), lançado no século XVIII e firmando-se ao longo do XIX, com a Revolução Industrial, um novo pensamento sobre o social (como o de Karl Marx) e passos iniciais da psicanálise. Mas a modernidade assumiria contornos mais nítidos no início do século passado, quando no Brasil procurou-se assumir um ensino superior aberto não só aos jovens do país, mas a uma parcela da juventude da América Latina, numa perspectiva integradora. Nesse contexto, constituiu-se o estudo da ciência da informação no país.

Originada quando os efeitos da Segunda Guerra Mundial determinaram a emergência de ramificações do saber e de transformações nas atividades de pesquisa, a ciência da informação caracteriza-se como uma ciência social, mas fortemente influenciada por 
outros campos de conhecimento que a definem e determinam seu domínio.

Ao analisar sua evolução, Saracevic identifica três características constituintes da razão de existência e da evolução da ciência da informação: sua natureza multidisciplinar, sua ligação à tecnologia da informação e sua participação ativa e deliberada na evolução da sociedade da informação (1996, p. 42). Nessa trajetória, em que se destaca como objeto científico a informação, os esforços no sentido de sua recuperação revestem-se de um caráter pragmático, cuja influência se verifica, segundo o autor, na indústria informacional, setor responsável pela criação e distribuição de dados e serviços online, decorrentes, assim como pelo acesso e disseminação da informação.

Com essa evolução de saberes e práticas a eles relacionadas, destacam-se novos conceitos e suas respectivas definições, concretizados em domínio científico específico.

Reiterando a importância do conceito de domínio para o presente estudo, apoiamos-nos em Lloyd, que o considera um recurso para constituir teoricamente objetos de investigação (1995, p. 25).

Será possível, a partir dessa constituição teórica, incorporar conhecimentos que contribuam também para a compreensão da história e dos saberes acumulados da ciência que se está analisando. Justifica-se, portanto, a preocupação do presente estudo em explorar a terminologia, uma vez que não se pode chegar ao domínio da ciência da informação, sem explorar os termos que fazem parte de sua constituição.

Tomada aqui como um conjunto de termos de uma especialidade (DIAS, 2000, p. 90), a terminologia tem sido especialmente valorizada para sistematização de bases de dados, arquivos e outros tipos de suportes eletrônicos de informação.

Considerando-se o aspecto constitutivo de um campo científico pelos termos que o representam, por um lado, e por outro, a necessidade de organizar o grande volume de dados passíveis de recuperação, adotandose um vocabulário controlado, temos que admitir o duplo papel da terminologia para este estudo. A análise temática e a reflexão dela decorrentes contribuirão para a elucidação do domínio da ciência da informação, assim como para a construção e consolidação da terminologia da área.

Foi com essas motivações que o Grupo de Pesquisa - Educação, Pesquisa e Perfil Profissional em Informação da Universidade Federal do Paraná, vinculado ao Núcleo de Produção Científica da Escola de Comunicação e Artes da Universidade de São Paulo - voltou-se ao estudo da produção científica da área de ciência da informação em artigos de revistas brasileiras. Sua proposta foi identificar e analisar na literatura científica da área de ciência da informação o recorte sobre a temática produção científica, sua natureza, características, estudos, aplicação e evolução.

O estudo foi instrumentalizado pela Base BRAPCI, uma base de dados referenciais de periódicos nacionais da área de ciência da 
informação que tem como objetivo principal subsidiar o projeto Análise bibliométrica das tendências na pesquisa em informação no Brasil e Espanha, registrada em fontes nacionais e internacionais, firmado entre a Universidade Federal do Paraná e a Universidad Carlos III de Madrid. A base de dados atualmente disponibiliza referências de 4057 textos publicados em 25 periódicos, nacionais impressos e eletrônicos da área de ciência da informação, de 1970 a 2006: Arquivística.net; Arquivo \& Administração; BIBLOS: Revista do Departamento de Biblioteconomia e História; Cadernos de Biblioteconomia; Ciência da Informação; Comunicação \& Informação; DataGramaZero; Em Questão: Revista da Faculdade de Biblioteconomia e Comunicação da UFRGS; Encontros Bibli; Estudos Avançados em Biblioteconomia e Ciência da Informação; ETD Educação Temática Digital; Informação \& Informação; Informação \& Sociedade: Estudos; Informare - Cadernos do Programa de PósGraduação em Ciência da Informação; Liinc em revista; Perspectivas em Ciência da Informação; Revista ACB: Biblioteconomia em Santa Catarina; Revista Brasileira de Biblioteconomia e Documentação; Revista da Escola de Biblioteconomia da UFMG; Revista de Biblioteconomia \& Comunicação; Revista de Biblioteconomia de Brasília; Revista Digital de Biblioteconomia \& Ciência da Informação; Revista do Departamento de Biblioteconomia e História; Revista Online da Biblioteca Prof. Joel Martins; Transinformação.

Tendo como referência para a análise o conjunto de artigos publicados nos periódicos científicos selecionados na Base BRAPCI e estruturados na Base PROCI, procurou-se identificar e mapear o conteúdo para reconhecer as características do discurso sobre a produção científica. Inicialmente foi necessário compatibilizar categorias temáticas para uma melhor estrutura do processo de análise, reduzindo a diversidade de termos muito específicos, pela sua inclusão em categorias mais abrangentes. Determinou-se, então, um recorte temático, a partir dos descritores relacionados no QUAD. 1.

QUADRO 1 - Relação de descritores sobre o tema Produção Científica

\begin{tabular}{|c|c|}
\hline $\begin{array}{l}\text { - } \quad \text { análise bibliométrica; } \\
\text { - } \quad \text { análise de domínio; } \\
\text { - } \quad \text { artigos; do discurso; } \\
\text { - } \quad \text { artigos científicos; } \\
\text { - } \quad \text { artigos de periódicos; } \\
\text { - } \quad \text { artigos de revisão; } \\
\text { - } \quad \text { avaliação científica; } \\
\text { - } \quad \text { bibliometria; } \\
\text { - } \quad \text { cienciometria; } \\
\text { - } \quad \text { cientometria; } \\
\text { - } \quad \text { comunicação científica; } \\
\text { - } \quad \text { discurso científico; } \\
\text { - } \quad \text { dissertações; } \\
\text { - } \quad \text { infometria; }\end{array}$ & $\begin{array}{ll}\text { - } & \text { informetria; } \\
\text { - } & \text { Lei de Bradford; } \\
\text { - } & \text { Lei de Zipf; } \\
\text { - } & \text { literatura científica; } \\
\text { - } & \text { literatura cinzenta; } \\
\text { - } & \text { periódicos; } \\
\text { - } & \text { periódicos científicos; } \\
\text { - } & \text { produção científica; } \\
\text { - } & \text { publicação científica; } \\
\text { - } & \text { revistas científicas; } \\
\text { - } & \text { teses; } \\
\text { - } & \text { trabalhos acadêmicos; } \\
\text { - } & \text { trabalhos científicos; } \\
\text { - } & \text { webmetria; } \\
\text { - } & \text { webometria. }\end{array}$ \\
\hline
\end{tabular}


Resultaram dessa estratégia, a partir destes descritores, 0 levantamento de 442 títulos de artigos relacionados ao tema produção científica, o que representa $10,9 \%$ da produção periódica total. Com base neste recorte, que denominaremos de corpus da pesquisa, foi possível identificar a temática em sua natureza, características, estudos, aplicação e evolução.

De acordo com o GRÁF. 1, é possível visualizar a distribuição de artigos por revista. O gráfico demonstra que a revista Ciência da Informação foi a que mais dedicou espaço para a temática, do total de 847 artigos publicados, 162 artigos foram sobre Produção científica $(19,1 \%)$. Os periódicos Arquivo \& Administração e Revista do Departamento de Biblioteconomia e História não publicaram qualquer artigo pertinente ao assunto.

A base de dados utilizada é ambientada no software ProCite, programa gerenciador de base de dados, criado pelo Institute of Scientific Information - ISI ResearchSoft, da qual foram retirados os títulos selecionados para a criação de uma nova base, denominada PROCI Produção Científica -, que passou a se constituir em corpus para análise desta pesquisa.

\section{Produção científica: tendências temáticas}

A análise sobre as tendências temáticas presentes nos artigos de periódicos demandou um trabalho inicial de padronização dos termos da base, para que se pudesse, então, reuni-los em grupos temáticos mais abrangentes e representativos de um espectro amplo de assuntos.

Entre os 442 títulos enfocados no estudo percebem-se três vertentes de preocupação: a produção científica propriamente dita, em suas manifestações, a análise dessa produção, e os tipos de produção, tais como, periódicos, teses, dissertações e literatura cinzenta. Ressalta o tema Revistas científicas com 134 incidências. Na seqüência, como pode ser observado no GRÁF. 2, as incidências mais significativas referem-se aos termos: Comunicação científica (84); Produção científica (81); Análise (48); Bibliometria (47); Publicação científica (42); Ciência da Informação (40); Avaliação científica (35); Informação (29); Literatura científica (24) e Leis da Ciência da Informação (22).

Percebe-se, como em estudos anteriores, que o enfoque bibliométrico desdobra-se em um conjunto semântico formado por termos como infometria (04 ocorrências), informetria (07), webometria (03), webmetria (01), cienciometria (11) e cientometria (01) e cibermetria (01). 


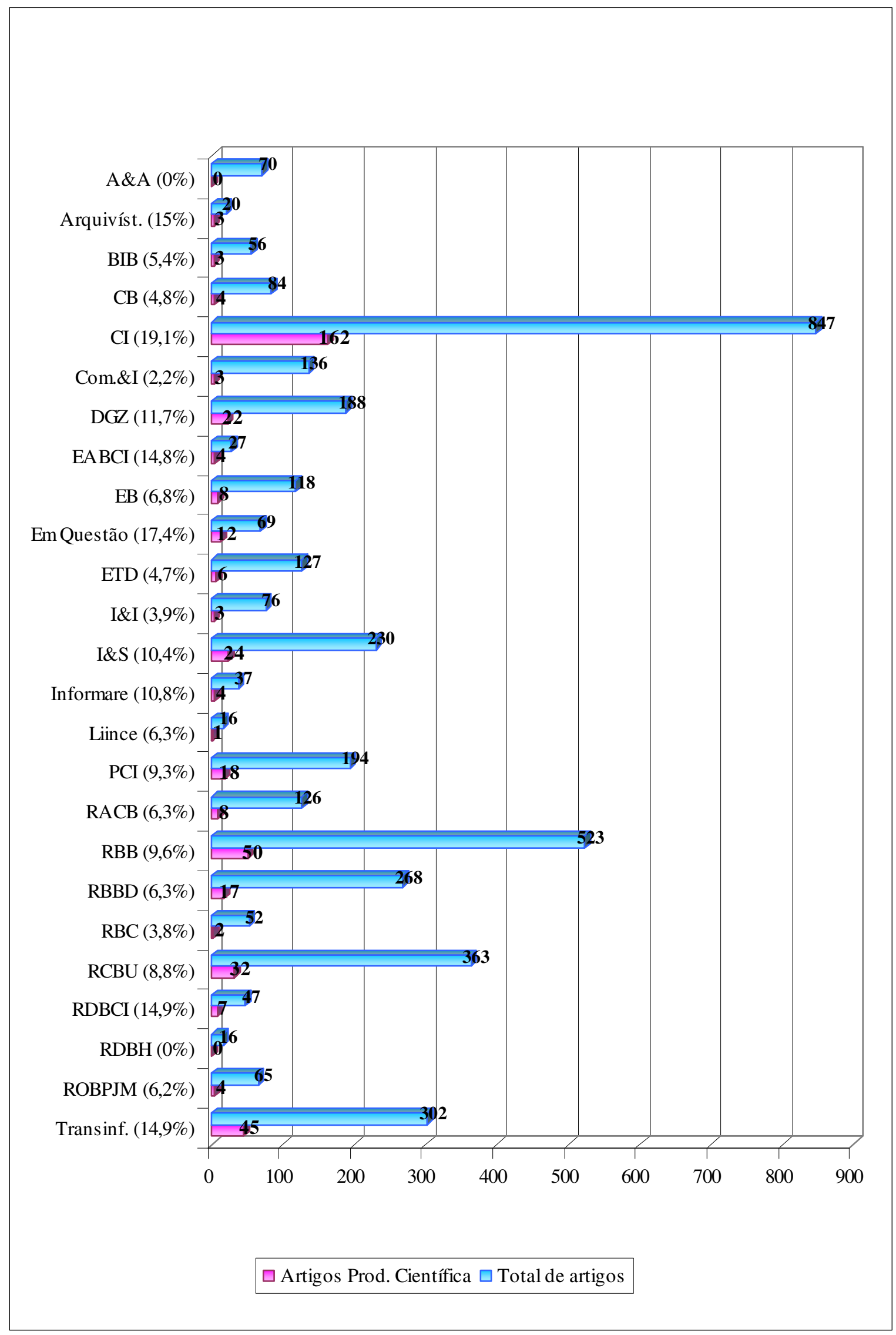




\section{GRÁFICO 1 - Distribuição de artigos sobre produção científica nos} periódicos de Ciência da Informação

Fonte: Os autores de acordo com a base BRAPCI

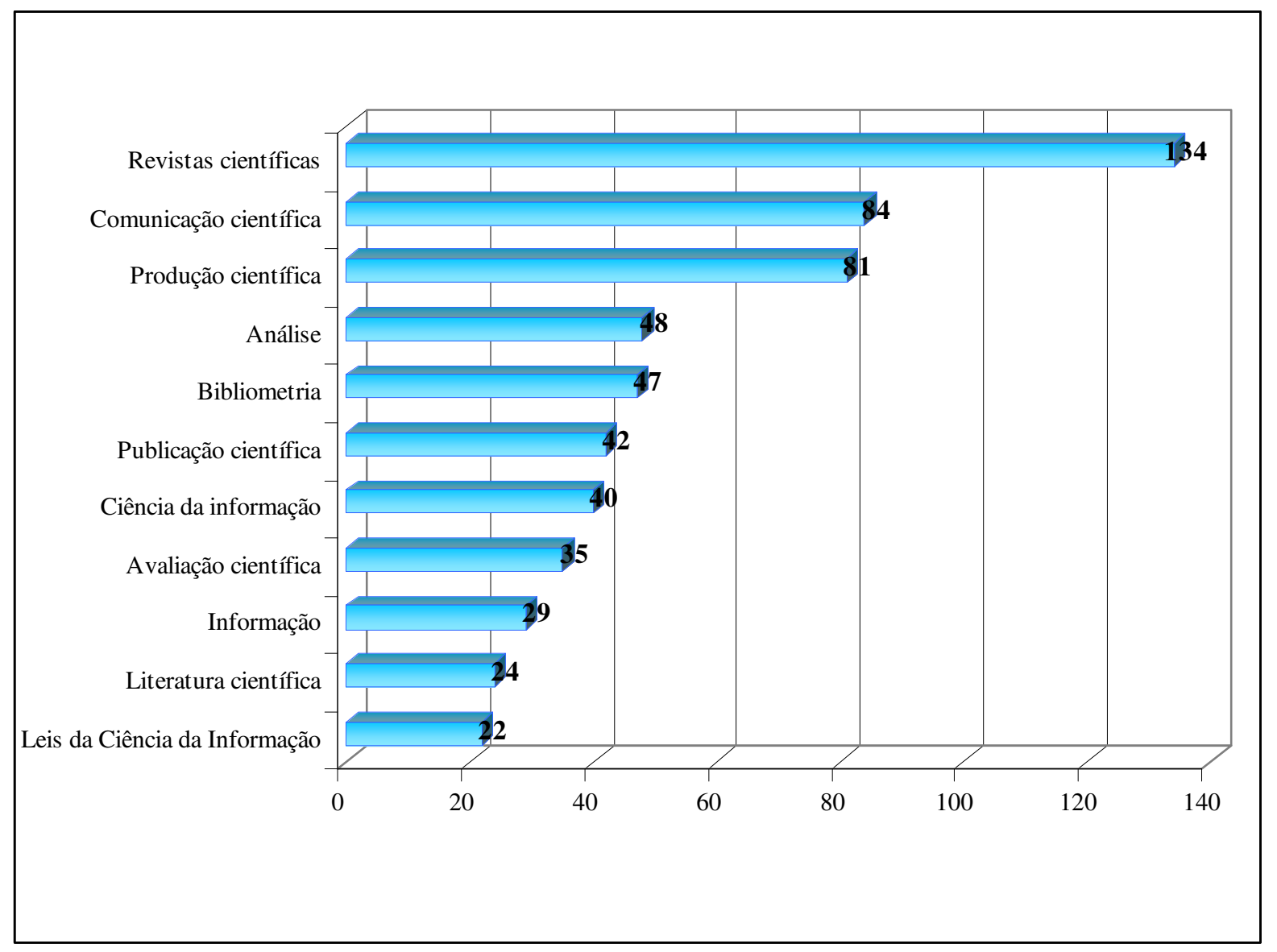

\section{GRÁFICO 2 - Descritores com maior incidência}

Fonte: Os autores de acordo com a base BRAPCI

Esse universo de termos, ainda incipiente, cujos pressupostos anunciam uma tendência temática que acompanha a evolução da produção científica, demonstra também as possibilidades oferecidas pela tecnologia da informação.

Assim, por exemplo, o termo infometria define-se como atividade mais ampla do que a bibliometria e a webmetria. Quanto à webmetria, mais recentemente destacada na literatura, tem sido denominada de webometria no Brasil e webmetria em outros países latinos. Em relação à cientometria, derivada do termo ciência, assim como cientista e científico, tem sido denominada no Brasil de cienciometria. Recentemente, tem sido utilizado também o termo cibermetria que, segundo Björneborn, tem escopo mais amplo que a webometria, pois compreende a aplicação das tradicionais técnicas informétricas a qualquer tipo de informação disponível na internet. Em relação a este termo, a webometria seria mais restrita, pois utiliza técnicas quantitativas para medir especificamente a 
informação disponível na web, apenas uma parte do universo maior da cibermetria (2002, apud VANTI, 2005).

A categoria produção científica é composta por uma pluralidade de termos sinônimos ou correlatos que indicam a necessidade, dentre outros aspectos, de padronização terminológica. Encontram-se nessa categoria, conforme o GRÁF. 3, termos como artigos científicos (12 ocorrências), avaliação científica (35), comunicação científica (84), literatura científica (24), pesquisa (21), produtividade científica (13), publicação científica (42), revistas científicas (134), teses e dissertações (20), trabalho científico (8) e o termo produção científica - objeto deste estudo - com 81 ocorrências.

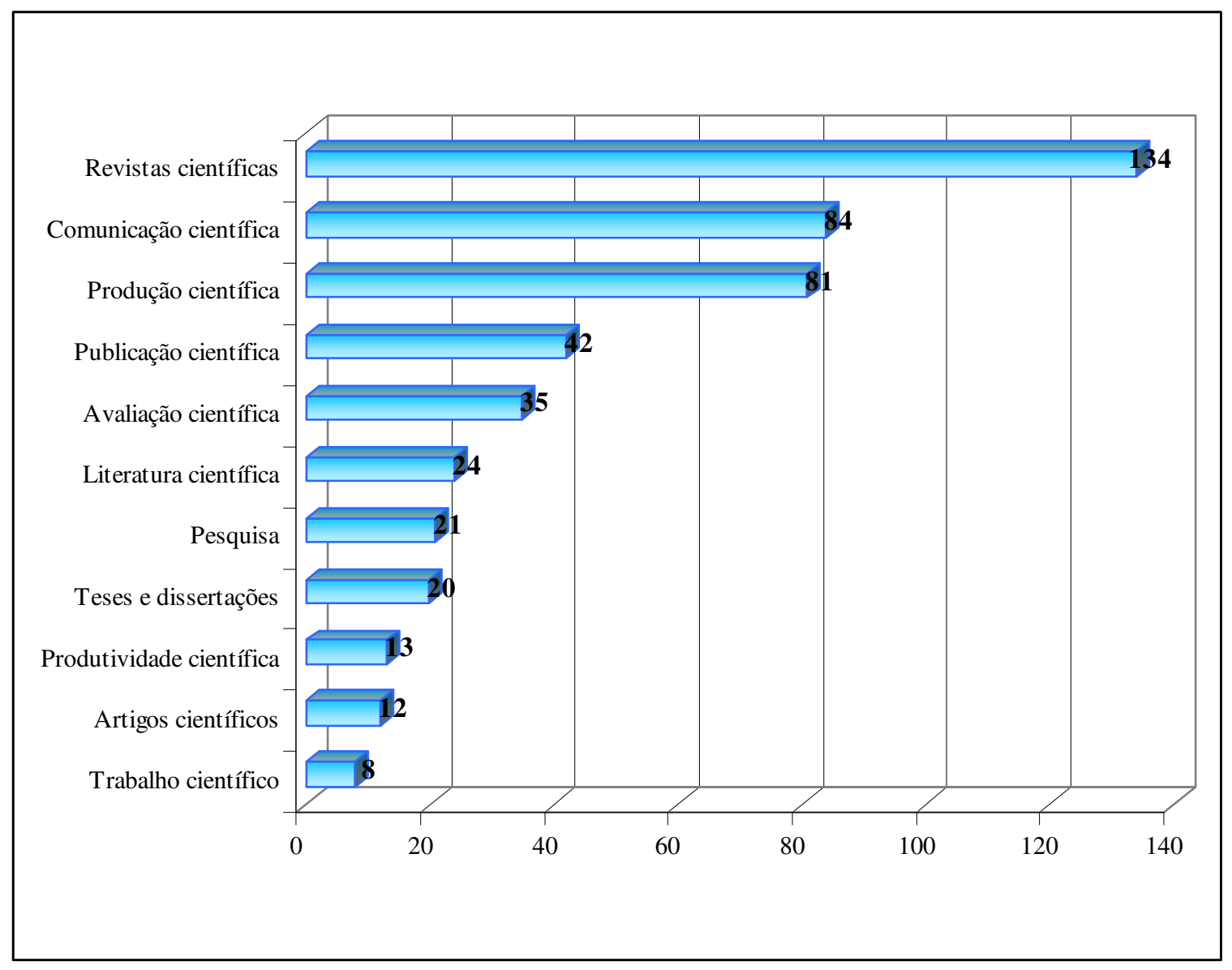

GRÁFICO 3 - Termos correlatos à produção científica

Fonte: Os autores de acordo com a base BRAPCI

Dentre os artigos encontrados na base de dados destacam-se alguns com o foco em análise (48 ocorrências), sejam elas bibliométricas, comparativas, de citações, de conteúdo, de/do discurso, de domínio, lingüísticas, metodológicas, qualitativas, quantitativas ou temáticas. Podese inferir que os autores, de certa forma, têm privilegiado na sua produção científica as questões analíticas de natureza diversa. 


\section{Considerações finais}

Ao analisar essa parcela da literatura sobre o tema Produção científica, evidencia-se a evolução de saberes e práticas a eles relacionadas, destacando-se novos conceitos e suas respectivas definições, concretizados em domínio científico específico.

Apresenta-se no corpus específico um complexo mapa conceitual para a construção de conhecimentos relacionados tanto com a temática produção científica e sua natureza, características, estudos, aplicação e evolução, quanto com a própria construção de domínio da ciência da informação.

Constata-se que, como afirma Hobsbawm (1998, p. 17), as palavras são testemunhas das transformações sociais. Esses termos passaram a fazer parte do cotidiano do campo da informação, representando os conceitos que compõem. Entretanto, deve-se ressaltar que a expansão temática nem sempre significa uma expansão de termos descritores em um tesauro ou em uma lista de palavras-chaves.

Percebe-se que há uma enorme diversidade de termos para representar os temas relacionados à produção científica. De fato, a profusão dos termos empregados para representar os temas relacionados ao objeto deste trabalho expressa a necessidade de cuidados nas questões terminológicas. Pode-se inferir que há a ausência de consolidação conceitual na análise e produção científica em ciência da informação. Essa lacuna pode ser, em parte, preenchida com estudos e levantamentos terminológicos que possibilitem a consolidação de uma linguagem de especialidade que contribuiria para a constituição do campo científico da área. Dito de outra maneira, nenhum campo científico se impõe no ambiente da pesquisa acadêmica se não dispuser de uma linguagem própria, ou seja, de uma linguagem especializada.

\section{Referências}

BJÖRNEBORN, Lennart. Small-world link structures on the web. Copenhagen, DK: School of Library and Information Science, 2002. Disponível em <www.db.dk/lb/2002smallworld.pps>. Acesso em 28 jul. 2003.

BUFREM, L. S. Linhas e tendências metodológicas na produção acadêmica discente do mestrado em Ciência da Informação do Instituto Brasileiro de Informação em Ciência e Tecnologia - Universidade Federal do Rio de Janeiro (1972-1995). 1996. Tese (Concurso para Professor Titular Métodos e Técnicas da Pesquisa) - Setor de Ciências Humanas, Letras e Artes, Universidade Federal do Paraná, Curitiba, 1996.

COELHO NETTO, José Teixeira. Moderno pós-moderno: modos \& versões. 3. ed. São Paulo: Iluminuras, 1995. 
DIAS, Cláudia Augusto. Terminologia: conceitos e aplicações. Ciência da Informação. Brasília, v. 29, n. 1, p. 90-92, jan./abr. 2000.

GRAMSCI, Antonio. Os intelectuais e a organização da cultura. Rio de Janeiro: Civilização Brasileira, 1988.

HOBSBAWM, Eric. J. A era das revoluções (1789-1848). Rio de Janeiro: Paz e Terra, 1998.

JANES, J. Some thoughts on education for the information professions. NFAIS Newsletter, v. 42, n. 9, p. 133-137, Sep. 2000.

LLOYD, Christopher. As estruturas da história. Rio de Janeiro: Zahar, 1995.

RUMMLER, Guido; SILVA, Viviane Rummler da. Longevidade e dispersão física de periódicos nacionais sobre pesquisa, ensino e educação. Educação Temática Digital, Campinas, v. 6, n. 2, p. 1-13, jun. 2005. Disponível em <http://143.106.58.55/revista/include/getdoc.php?id= 107\& article $=36 \&$ mode $=$ pdf $>$. Acesso em 17 jan. 2006.

SARACEVIC, Tefko. Ciência da Informação: origem, evolução e relações. Perspectivas em Ciência da Informação, Belo Horizonte, v. 1, n. 1, p. 41-62, jan./jun. 1996.

VANTI, Nadia. Os links e os estudos webométricos. Ciência da Informação, Brasília, v. 34, n. 1, p. 78-88, jan./abr. 2005. 